\title{
Patient-centred quality care: An assessment of patient involvement
}

Constance S. Shumba, Ruth Atukunda, Peter Memiah

Department of Outcomes and Evaluation, University of Maryland, Institute of Human Virology, Kampala, Uganda

Address for the Correspondence:

Dr. Constance Shumba, University of Maryland, Institute of Human Virology P O Box 2476, Kampala, Uganda. E-mail: konstansezw@gmail.com

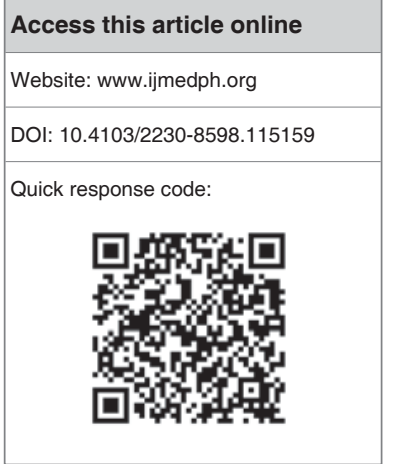

Background: There is limited research on patients' involvement in healthcare in Sub-Saharan Africa. Patients' involvement is important in improving health service delivery as well as health outcomes. Materials and Methods: A patients' involvement assessment was carried between September and November 2010 in 18 different health facilities using an interviewer administered checklist. The purpose was to assess patients' involvement from the provider perspective in HIV care hospitals and clinics with the aim of improving quality of care. A score ranging from zero to three was used to grade the different level of patient involvement at the health facilities. Results: Only $11 \%$ of the 18 different health facilities achieved the highest score of three, whereby consumer input is incorporated into setting quality goals and results of quality activities that are routinely communicated to patients and other consumers. The remaining $89 \%$ of the facilities had gaps with regard to patient involvement in health care. Conclusion: Majority of the facilities did not have structures that involve patients in quality improvement projects, advocacy and routinely communicating to patients and developing other patient centred quality activities. It is important to build sustainable and lasting partnerships for patients' involvement in health systems and health delivery. Patients' involvement should be placed as a fundamental priority in scaling up quality health services at the primary level.

Key words: Patient involvement, health providers, quality improvement

\section{INTRODUCTION}

There are multiple definitions for patients' involvement and this term is often used interchangeably with patients' participation, patients' engagement and patients' centred care..$^{[1,2]}$ Quality improvement is becoming an important component of health care world over and there is growing recognition in the literature of the contribution patients can make to improve health outcomes. ${ }^{[3,4]}$ Involving patients in different aspects of their health care is seen as an important part of improvement in decision making and developing client-centred care in the health care setting. ${ }^{[2,5]}$ Patients contribute to their safety by reporting prevention of side effects and errors. ${ }^{[6-9]}$

The level of patient involvement in health is variable and in countries such as the United Kingdom it is well established. ${ }^{[10]}$ In contrast, in other settings there is a dearth of evidence on the role of patients in improving quality and safety of health services. ${ }^{[1]} \mathrm{A}$ review of patients' participation in Africa revealed a gap in patient participation research in Sub-Saharan Africa. ${ }^{[12]}$ This suggests that there may be little focus on patients' involvement approaches or if strategies exist they have not been evaluated and documented.

The purpose of this assessment was to determine the level of patient involvement from the provider perspective in health care and thus contribute to improved quality of care.

\section{MATERIALS AND METHODS}

In Uganda there are about 1.1 million people living with HIV (PLHIV) and over 200,000 are on treatment. ${ }^{[13]}$ This study was conducted in 18 different health facilities providing care and treatment to more than 80,000 PLHIV rural and urban under-served communities in the Northern, Southern, Central, Eastern and Western regions of Uganda. Most of the facilities are faith-based and not-for-profit and began providing care and treatment in March 2004. All of the facilities participated in quality 
improvement initiative to strengthen their programming and technical capacities and applying evidence based data to improve care, treatment and community follow up.

All 18 different health facilities were included in assessment of patients' involvement. An interviewer administered checklist was developed and administered at the facility. Health workers were trained to administer the tool prior its administration. A scale of 0-3 was used to grade the different scores with 0 as the least and 3 as the highest score. Data was summarized on an excel sheet and the mean, median and performance of patients' involvement at the facilities were determined. The checklist was developed by the University of Maryland, IHV as part of a tool for annual site capacity assessment. The scale and descriptors for assessing patients' involvement is shown in Table 1.

\section{RESULTS}

Only two $(11 \%)$ of the 18 facilities achieved the highest patient involvement score whereby consumer input is incorporated into setting quality goals and results of quality activities are routinely communicated to patients and other consumers. The remaining $88 \%$ of the facilities had gaps with regard to patient involvement in health care. Some $(39 \%)$ of the facilities reported addressing patient concerns as they arose, patients' satisfaction was not routinely measured and there was no structure in place to gather patients' feedback. Half $(50 \%)$ of the facilities reported that patient needs and/or satisfaction was assessed and the feedback from patients was discussed in quality committee. Figure 1 shows the results.

\section{DISCUSSION}

Our assessment found that only $11 \%$ of the facilities had a high level of patients' involvement. Some of the facilities assessed patients'

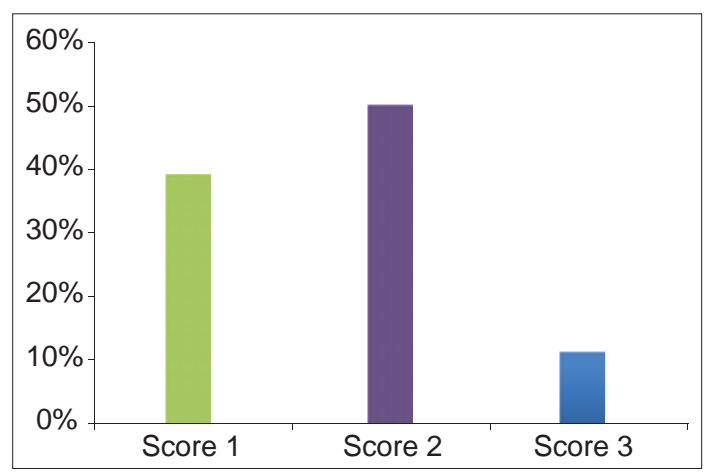

Figure 1: Patient involvement assessment scores needs and discussed these in quality committees. However, it appears they did not incorporate these needs into setting quality goals and results of quality activities were not routinely communicated to patients and other consumers. Furthermore, some of the facilities addressed patient concerns as they arose, patients' satisfaction was not routinely measured and there was no structure in place to gather patients' feedback. This confirms the lack of patients' involvement in health care decision-making with a lack of systematic planning and prioritization of patients' involvement in health care. In a study conducted in Uganda, among women with breast cancer, 80\% reported that they were not given a chance to participate in treatment selection. ${ }^{[14]}$ In addition, $51.6 \%$ believed that patients had no right to participate in the treatment decision making process. In contrast in another study, HIV/AIDS patients were generally active in making treatment decisions with their providers, garnering information about anti-retroviral treatments from a variety of sources including peers, family members, health professionals and the media. ${ }^{[15]}$ A major limitation of this study is that it was conducted in the United States which is a different context from our study setting.

Whilst patients are traditionally seen as the health care clients ${ }^{[16]}$ this view is changing with health care professionals also viewed as internal clients and patients as external clients. ${ }^{[17]}$ This exerts demands on the system to meet the expectations of both forms of clients. Some authors postulate that clients encourage competition between healthcare providers therefore contributing to quality improvement in health. ${ }^{[16,18]}$ However, this may not necessarily apply in some low income contexts where the choice of providers is limited and clients have a limited opportunity to do this. At the worst, bad quality service limits access to health care as people choose not to access the limited providers. Auditing the quality of the health care delivery services is essential in ensuring that service quality is optimal. In Pakistan and Sri Lanka, clients travelled long distances by passing proximal health facilities due to poor quality care. ${ }^{[19]}$ Client feedback should form the bedrock of service quality ${ }^{[20]}$ and use the mechanisms of generating feedback as tools such as suggestion boxes and surveys to improve quality of care. Whilst most models of patients' involvement in the treatment setting have been criticized for being narrowly inclined towards interpersonal communication with providers, ${ }^{[7]}$ clients usually look at the interpersonal skills as a measure of quality while clinicians look at their technical skill. ${ }^{[20]}$ As such a good technical skill is of no value if not accompanied with good interpersonal skills.

In a study of patients treated in US acute care hospitals, patients' participation was found to be highly linked with positive opinions about hospital quality. ${ }^{[21]} \mathrm{A}$ number of factors have been found

\begin{tabular}{|c|c|c|c|c|}
\hline Score & 0 & 1 & 2 & 3 \\
\hline Descriptor & $\begin{array}{l}\text { No process } \\
\text { for patients' } \\
\text { involvement } \\
\text { or for } \\
\text { addressing } \\
\text { patient } \\
\text { concerns }\end{array}$ & $\begin{array}{l}\text { Patient concerns } \\
\text { address as they arise; } \\
\text { Patients' satisfaction } \\
\text { not routinely } \\
\text { measured; no structure } \\
\text { in place to gather } \\
\text { patient feed back }\end{array}$ & $\begin{array}{l}\text { Patient needs and/ } \\
\text { or satisfaction } \\
\text { is assessed; } \\
\text { feedback from } \\
\text { patients is } \\
\text { discussed in } \\
\text { quality committee }\end{array}$ & $\begin{array}{l}\text { Findings of the consumer assessment are routinely integrated } \\
\text { into the quality program; QI projects reflect the results of issues } \\
\text { identified by the consumer; There is structured input from } \\
\text { the consumer such as patient, family member or advocate; } \\
\text { consumer input is incorporated into setting quality goals; results } \\
\text { of quality activities are routinely communicated to patients and } \\
\text { other consumers; patient centred quality activities are launched }\end{array}$ \\
\hline
\end{tabular}


to limit patients' participation by health workers. These include the desire to maintain control, heavy workload limiting provider patients' interaction, nature of patient's illness, the health workers own personal beliefs and knowledge and ability to foster patient involvement. ${ }^{[1]}$ On the other hand factors that influence patients' involvement were found to be patients' literacy levels and role acceptance, self confidence, the nature of decision-making and demographic characteristics. ${ }^{[1,22]}$ Low income countries suffer from waning consumer confidence in the health system due persistently poor service such as long waiting times, drug stock-outs, staff rudeness among others. Additionally, this poor service is all some patients ever know and low levels of literacy exacerbate this. ${ }^{[23]}$ Stakeholder commitment is essential in building a strong culture of quality ${ }^{[24]}$ and the staff can buy into quality improvement efforts and quell fears of increased workload if they are integrated within the entire system and benefits are clearly explained. ${ }^{[25,26]}$

The social distance between providers and patients presents a huge challenge in low income countries. ${ }^{[1,22,27]}$ The lack of meaningful participation of clients in health care can be overcome by engaging community liaisons, ${ }^{[28]}$ needs assessment and through education and information exchange. ${ }^{[29]}$ Whilst patients may not really know their rights, involving them can improve that knowledge and awareness of client entitlements and roles over time. ${ }^{[22]}$ Adopting a client centred approach using participatory methods improves outcomes and training of health workers can be useful in achieving this. ${ }^{[30]}$ Some of the strategies to improve patient involvement include meaningfully engaging patient or community representatives on quality improvement committees' teams, asking expert clients to volunteer, increasing contact and feedback from patients' support groups, carrying out patients' satisfaction surveys. Health workers can engage in effective communication with clients by clearly explaining diagnosis, disease etiology, treatment, adherence and prevention the dosages of the medications to be used. Information must be delivered to clients in simple non-technical terms that are easy to understand and culturally appropriate. Informed clients are in a better position to negotiate good quality services and evaluate the standard of care offered.

It is necessary to engage communities as stakeholders in health programs. ${ }^{[31]}$ Periodic meetings with the community members, introduction of suggestion boxes, toll free line for ease of contact and updating the notice board for clients could improve the contact gap between providers and patient and streamline user perspectives into health service delivery. In addition, the internal clients, health care workers must develop quality improvement strategies and this must be accompanied by resources to translate strategies into reality. ${ }^{[32]}$ Notwithstanding, the weak health systems present a major hurdle in quality improvement efforts.

\section{Limitations}

One major limitation is that the assessment and strategies were from the provider perspective and not the patients' perspective. Therefore, they may not adequately represent the patients' perspective.
However, it is believed that this would be a first step to get providers to start seeking out ways in which patients would be involved in quality improvement. Another weakness of this assessment is that we did not evaluate the effectiveness of patient involvement strategies and could not therefore link these to client outcomes.

\section{Implications for health programs and policy}

The findings in this paper suggest the need for ensuring meaningful participation of clients in defining the policy agenda as well as programme implementation with a view to improving quality of health comprehensive health care. For this to happen effectively, improvements in human resource capacity in the health system must also be made.

Information exchange in the healthcare setting is affected by health worker shortages thereby increasing focus on mere output. Consequently, achieving high quality of care and client satisfaction calls for institutional reforms in quality improvement and human resource capacity. Health organizations can effectively serve the clients if they are informed about the wide array of needs and priorities through collaboration and consultation with the clients both at policy and implementation levels. Once these strategies are employed it is necessary to assess their effectiveness in light of the environmental influences and continuously endeavour to find ways of meaningfully engaging and incorporating the voices of patients in health service delivery.

Whilst HIV/AIDS treatment programs have had considerably tremendous support with PLHIV associations and support groups more needs to be done in terms of effectively engaging PLHIV in health quality improvement. Equally important is the need to strengthen the health system instead of perpetuating vertical structures for HIV services. More research is needed on the perspectives and roles of patients in quality improvement in health care.

\section{CONCLUSION}

Patients' involvement is important in reforming health systems. It ensures that the voices and needs of service users are incorporated in health delivery because of a strong service user perspective in all decision making and service delivery processes thus, improving the quality of life through responsiveness to their health needs. It is therefore, important to streamline the voices of patients in decision making not only in health but in every aspect of life that affects health and wellbeing. Good quality care can be achieved if there is a coordinated systematic support for patients' involvement efforts. Strategies to achieve meaningful patients' involvement need to be explored contextually and harnessed to achieve better health outcomes.

Patients' involvement in health delivery decision-making and quality improvement efforts facilitates the removal of barriers that clients face in seeking health care especially chronic HIV care. Client focused initiatives are more empowering and increase participation 
in health. Collective engagement in improving health care quality must include the interests of all including the marginalized as well as create an enabling environment for participation in activities. In the transitional phases of quality improvement there is need for integration of patients' involvement in health and possible best practices. This includes building skills for positive transformation and involving the custodians of health service delivery in leading and implementing patient involvement activities in order to improve health service delivery. As we forge ahead, building sustainable and lasting partnerships for patient involvement in health systems and health delivery ought to be an integral part of the process. Patient involvement should be placed as a fundamental priority in scaling up health services at primary level.

\section{ACKNOWLEDGMENT}

AIDSRelief sites, UMSOM-IHV Uganda, UMSOM-IHV Baltimore, PEPFAR Team, CDC-Uganda.

\section{REFERENCES}

1. Longtin Y, Sax H, Leape LL, Sheridan SE, Donaldson L, Pittet D. Patient participation: Current knowledge and applicability to patient safety. Mayo Clin Proc 2010;85:53-62

2. Longtin Y, Sax H, Allegranzi B, Hugonnet S, Pittet D. Patients' beliefs and perceptions of their participation to increase healthcare worker compliance with hand hygiene. Infect Control Hosp Epidemiol 2009;30:830-9.

3. Coulter A. When should you involve patients in treatment decisions? $\mathrm{Br} \mathrm{J}$ Gen Pract 2007;57:771-2.

4. Groene OO, Jorgensen SJ. Health promotion in hospitals: A strategy to improve quality in health care. Eur J Public Health 2005;15:6-8.

5. Staniszewska S, Herron-Marx S, Mockford C. Measuring the impact of patient and public involvement: The need for an evidence base. Int J Qual Health Care 2008;20:373-4.

6. Davis RE, Jacklin R, Sevdalis N, Vincent CA. Patient involvement in patient safety: What factors influence patient participation and engagement? Health Expect 2007;10:259-67.

7. Entwistle VA, Watt IS. Patient involvement in treatment decision-making: The case for a broader conceptual framework. Patient Educ Couns 2006;63:268-78.

8. Koutantji M, Davis R, Vincent C, Coulter A. The patient's role in patient safety: Engaging patients, their representatives, and health professionals. Clin Risk 2005;11:99-10.

9. Vincent CA, Coulter A. Patient safety: What about the patient? Qual Saf Health Care 2002;11:76-80.

10. Mockford C, Staniszewska S, Griffiths F, Herron-Marx S. The impact of patient and public involvement on UK NHS health care: A systematic review Int J Qual Health Care 2012;24:28-38.

11. Davis RE, Jacklin R, Sevdalis N, Vincent CA. Patient involvement in patient safety: What factors influence patient participation and engagement? Health Expect 2007;10:259-67.

12. Upham G, Kadi AM, Ndi JM, Sano M. Patients' involvement in patient safety research in Africa. Tropical Diseases Research to Foster Innovation and Knowledge Application, 2005.

13. MOH. 2010. Uganda UNGASS Progress Report, Jan 2008-Dec 2009. Uganda.

14. Batte A, Odoi-Adome R. Patient involvement in treatment decision making among women with breast cancer: Creating person-centred and equitable health service systems. Paper produced as part of a Capacity building programme of the Regional Network on Equity in Health in east and southern Africa (EQUINET), May 2006.
15. Marelich WD, Johnston Roberts K, Murphy DA, Callari T. HIV/ AIDS patient involvement in antiretroviral treatment decisions. AIDS Care 2002;14:17-26.

16. Donabedian A. The Lichfield Lecture. Quality assurance in health care: Consumers' role. Qual Health Care 1992;1:247-51.

17. Walley J, Wright J. Public health: An action guide to improving health. $2^{\text {nd }}$ ed. Oxford: Oxford University Press; 2010.

18. Hibbard JH. Engaging Health Care Consumers to Improve the Quality of Care. Med Care 2003;41:161-70.

19. WHO. Quality of care: A process for making strategic choices in health systems [Online]. Geneva: World Health Organization. 2006. Available from: http://www.who.int/management/quality/assurance/QualityCare_B. Def.pdf [Last accessed on 2012 Sep 18].

20. Frattali CM. Measuring Client Satisfaction. [Online] 2012. Available from: http://www.asha.org/SLP/healthcare/Measuring-Client-Satisfaction/[Last accessed on 2012 Dec 13].

21. Weingart SN, Zhu J, Chiappetta L, Stuver SO, Schneider EC, Epstein AM, et al. Hospitalized patients' participation and its impact on quality of care and patient safety. Int J Qual Health Care 2011;23:269-77.

22. Marincowitz GJ. Mutual participation in the health worker-patient relationship. SA Fam Pract 2004;46:30-3.

23. Mugisha F, Bocar K, Dong H, Chpng'eno G, Sauerborn R. The two faces of enhancing utilization of health-care service: Determinants of patien initiation and retention in rural Burkina Faso. Bull World Health Organ 2004;82:572-9.

24. Omaswa F, Burnham G, Baingana G, Mwebesa H, Morrow R. Introducing quality management into primary health care services in Uganda. Bull World Health Organ 1997;75:155-61.

25. Leatherman S, Ferris TG, Berwick D, Omaswa F, Crisp N. The role of quality improvement in strengthening health systems in developing countries. Int J Qual Health Care 2010;22:237-43.

26. Massoud, Askov RK, Reinke J, Franco LM, Bornstein T, Knebel E, et al. A modern paradigm for improving healthcare quality, QA Monograph Series, 1 (1) [Online]. Bethesda, MD: Published for the U.S. Agency for International Development (USAID) by the Quality Assurance Project; 2001.

27. IAPO. 2009. Working Together to Strengthen Healthcare Systems in Africa. A report of the November 2008 meeting held in Kampala, Uganda. International Alliance of Patients' Organizations.

28. Pivik JR. Practical Strategies For facilitating Meaningful Citizen Involvement in Health Planning [Online] 2002. Available from: http://publications.gc.ca/collections/Collection/CP32-79-23-2002E.pdf [Last accessed on 2012 Oct 13].

29. Darby C, Valentine N, Murray JL, De Silva A. World Health Organization (Who): Strategy On Measuring Responsiveness, 23, [Online] 2000. Available from: http://www.who.int/healthinfo/paper23.pdf [Last accessed on 2012 Oct 9].

30. Lantis K, Green CP, Joyce S. Providers and Quality of Care-Population Reference Bureau. [Online] 2002. Available from: http://auth.prb. org/Publications/PolicyBriefs/ProvidersandQualityofCare.aspx [Last accessed on 2012 Nov 3].

31. Smith BL. Public Policy and Public Participation Engaging Citizens and Community in the Development of Public Policy [Online] 2003. Available from: http://www.phac-aspc.gc.ca/canada/regions/atlantic/pdf/pub_policy_ partic_e.pdf [Last accessed on 2012 Oct 22].

32. Dieleman M, Harnmeijer J. "Improving health worker performance: In search of promising practices" In. "WHO" [Online.] 2006. Available from http://www.who.int/hrh/resources/improving_hw_performance.pdf [Last accessed on 2012 Sep 9].

How to cite this article: Shumba CS, Atukunda R, Memiah P. Patient-centred quality care: An assessment of patient involvement. Int J Med Public Health 2013;3:77-80.

Source of Support: The study was conducted within the AIDS Relief hospitals, Conflict of Interest: None declared. 